\title{
Effect of Short-term Probiotic Yogurt Consumption on Caries Risk Factors in Infants
}

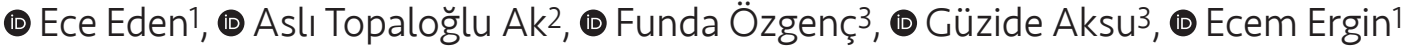 \\ ${ }^{1}$ Ege University Faculty of Dentistry, Department of Pediatric Dentistry, İzmir, Turkey \\ 2Istanbul Aydın University Faculty of Dentistry, Department of Pediatric Dentistry, İstanbul, Turkey \\ ${ }^{3}$ Ege University Faculty of Medicine, Department of Pediatric Gastroenterology, Izmir, Turkey
}

\begin{abstract}
Aim: We aimed to evaluate the effect of short-term probiotic yogurt consumption on $\mathrm{pH}$, buffering capacity, and Streptococcus Mutans, Lactobacilli and secretory immunoglobulin A ( $\lg$ A) levels in saliva of 6-8 months old healthy infants.

Materials and Methods: Twenty healthy infants and their mothers were enrolled in the study. They were randomly allocated into two groups as study and control. In the study group, probiotic yogurt (Bifidobacterium Longum BB536, Bifidobacterium Bifidum Bb12, Lactobacillus Rhamnosus HN001) was given to infants for 3 weeks whereas, in the control group, home-made yogurt was consumed. A dental saliva pH-Indicator strip (GC, Japan) was used for salivary pH measurements. Buffering capacity was determined using CRT buffer (Ivoclar Vivadent, Liechtenstein). The counts of salivary mutans streptococci and lactobacilli were evaluated using CRT bacteria (Ivoclar Vivadent, Liechtenstein). ELISA was used for sIgA. Scores at baseline and three weeks after were statistically evaluated by Wilcoxon test using the IBM SPSS 20.0 program.

Results: Salivary pH, IgA, S. mutans and lactobacilli values showed no significant change after 3 weeks of probiotic yogurt consumption, however there was a statistically significant increase in the buffering capacity of saliva $(p=0.04)$.

Conclusion: Short-term probiotic yogurt intervention in infants during the early stages of life might have benefits for oral health. Further studies with both short- and long-term use of probiotics must be implemented in infants to confirm the results and see the effects on other caries risk factors.
\end{abstract}

Keywords: Infants, short term probiotics, caries risk factors

\section{Introduction}

In today's market, the consumption of probiotic dairy products namely yogurt, cheese or ice cream is increasing with the media drawing attention to their promotive effects on general health $(1,2)$. The beneficial effect of probiotic bacteria on intestinal microbial balance and immunity is still a matter of interest for researchers (3-5). These products come into contact with the oral cavity and so their immune overall effect may possibly cause an alteration of oral microbiota as well. Today, many studies have demonstrated not only their general health benefits but also their oral health benefits (2,6-15).

In recent decades, dental researchers have investigated probiotic-containing products as a preventive measure in dentistry. From an oral health perspective, these studies have been mainly conducted on children and young adults with various different probiotic containing foods, drinks and supplements (2,6-15). Today, probiotic is also integrated into infant nutrition such as infant formulas. They are on the

\section{Address for Correspondence}

Aslı Topaloğlu Ak DDS, PhD, Istanbul Aydın University Faculty of Dentistry, Department of Pediatric Dentistry, istanbul, Turkey Phone: +90212 4113000 E-mail: asliak@aydin.edu.tr ORCID ID: orcid.org/0000-0003-4572-1875

Received: 31.05 .2018 Accepted: 07.09.2018

${ }^{\circ}$ Copyright 2019 by Ege University Faculty of Medicine, Department of Pediatrics and Ege Children's Foundation The Journal of Pediatric Research, published by Galenos Publishing House. 
shelves of markets aiming to compensate for human breast milk. In addition, natural probiotic containing baby foods like yogurts, gruel and cereals are gaining in popularity by promising good health from the first years of life (16).

Particularly, the first year of life plays a vital role in the formation of oral microbiota which may affect the probability of caries risk of the child. Lately, researchers have examined initial microbial colonization and salivary components of healthy full-term infants (17-19). Thus, researches have conducted studies on infants to see the effect of early intervention of probiotics on caries formation in the long-term. One such study by Stensson et al. (20) showed that daily supplementation of probiotics from birth and during the first year of life results in decreased caries prevalence and improved periodontal health even after 9 years. The other interesting finding was that children receiving probiotics tend to have a higher secretory immunoglobulin A (slgA) level in the long term, however, there was no statistically significant difference noted.

Although the outcomes of studies present variations due to different strains of probiotics use, and methodologies, the idea that the consumption of probiotics can alter the oral microbiota and salivary components remains worthy of investigation.

To our knowledge, there is very limited data that demonstrates the effect of probiotic consumption on caries risk factors and salivary antibodies in infants. Hence, the present study aims to evaluate the effect of short-term probiotic yogurt consumption on $\mathrm{pH}$, buffering capacity, and Streptococcus mutans, Lactobacilli and slgA levels in the saliva of 6-8 month-old healthy infants.

\section{Materials and Methods}

This case control study was a part of short-term research that was supported by Ege University Scientific Research Committee, performed at the Department of Pediatric Dentistry and Healthy Baby Clinic of the Faculty of Medicine. Ethical approval was given by the Research Ethics Committee Faculty of Medicine at Ege University (approval number: 12-8/24). Healthy 6-8 month-old infants who were referred to the healthy baby clinic for their periodic examination and their mothers were recruited for the study. Prior to the commencement of the investigation, informed consent for infants was provided by their parents. The inclusion criteria were full term born and caesarean section infants with no systemic disease or immunological deficiency whereas exclusion criteria for both infants and mothers were; use of antibiotics within 1 month prior to the study.

At the start of the study, 27 babies and their mothers were recruited. The baby-mother pairs were randomly allocated into two groups as study and control. In the study group, probiotic yogurt (Bifidobacterium Longum BB536, Bifidobacterium Bifidum Bb12, Lactobacillus Rhamnosus HN001) was given to infants as a morning snack for 3 weeks, whereas, in the control group, home-made yogurt was consumed. A consumption chart with a 3-week duration was given in order to ensure that the babies were consuming the assigned yogurts at the proper amounts. Unfortunately, 7 of the baby-mother pairs were taken out of the study due to antibiotic use, irregular yogurt consumption or failure to follow up. As a result, findings for twenty 6-8 month-old infants and their mothers were reported.

Prior to dental examination, the head diameters, weight and height of the infants were measured and reported as $40.87 \pm 1.27 \mathrm{~cm}, 7.69 \pm 0.81 \mathrm{~kg}$ and $64.56 \pm 2.73 \mathrm{~cm}$ respectively. Two trained examiners conducted all the clinical oral examinations. At baseline, the infants were examined using a sterile dental mirror and artificial light in the knee-to-knee position.

The mothers and infants were asked not to receive food or drink for 30 minutes prior to the first visit. An unstimulated saliva sample was collected from each child with a sterile cotton roll. The cotton roll was kept in the mouth of the infant until it was completely wet. Then these rolls were put in a small polypropylene tube with holes at the bottom. The small tube was then placed in a larger sterile polypropylene tube with a conical bottom. Both of the tubes, one within the other, were centrifuged to drain the saliva through the cotton roll. Subsequently, $1 \mathrm{~mL}$ of the saliva sample was sent to a laboratory within half an hour and stored at $-92^{\circ} \mathrm{C}$ until investigated for IgA.

The remaining saliva samples were used immediately to obtain the baseline buffering capacity, $\mathrm{pH}$ and bacterial counts using chair-side tests. The same procedures were conducted at third week recall.

In the mothers' group, un-stimulated saliva samples were collected for $\mathrm{pH}$ measurements. The mothers were asked to sit still for 5 minutes and then asked to lean their head downward and split the accumulated saliva into sterile tubes for 5 minutes. For stimulated saliva, mothers were asked to chew a paraffin block and after swallowing the first accumulated saliva, they were asked to spit as they chewed for 5 minutes. $1 \mathrm{~mL}$ of this stimulated saliva was sent to the laboratory for IgA evaluation.

A pH-Indicator strip (GC, Japan) was used for salivary $\mathrm{pH}$ measurements. Unstimulated saliva samples from the mothers and infants were examined and the color changes on the $\mathrm{pH}$ strips were recorded immediately.

Buffering capacity was assessed using CRT buffer (Ivoclar Vivadent AG, Schaan, Principality of Liechtenstein). 
According to the manufacturer's instructions, stimulated samples were used. This was possible for the mothers but for the infants unstimulated saliva was used. The test strip was placed on a stable, absorbent paper with the yellow test field facing upwards. The entire yellow test field was wetted with saliva using a pipette to prevent the formation of bubbles. To determine the buffer capacity of saliva, the color of the test field was compared with the color samples after exactly 5 minutes of reaction time. A blue color indicated high, while green showed medium and finally yellow demonstrated low buffer capacity of saliva.

The CRT bacteria (Ivoclar Vivadent AG Schaan, Principality of Liechtenstein) was used in accordance with the manufacturer's instructions to determine the counts of salivary mutans streptococci and lactobacilli. Stimulated saliva was collected from the mothers but un-stimulated saliva of the babies was used for bacterial evaluation.

Briefly, saliva samples both from the infants and mothers were inoculated on a dip-slide with selective agar media and it was cultivated at $37^{\circ} \mathrm{C}$ for 48 hours. The colony forming unit density for both salivary mutans streptococci and lactobacilli was compared against a chart provided by the manufacturer. Samples were categorized as group 1, 2, 3 and 4 (Figure 1 and 2).

$1 \mathrm{~mL}$ saliva samples were kept in $-92{ }^{\circ} \mathrm{C}$. After all the sampling was done for infants and their mothers, both for baseline and third week recall, ELISA (IBL International $\mathrm{GMBH}, \mathrm{Hamburg}$, Germany) was used for the measurement of salivary slgA.

\section{Statistical Analysis}

Baseline and three-weeks-after scores were statistically analyzed by the Wilcoxon test using IBM SPSS 20.0 program.

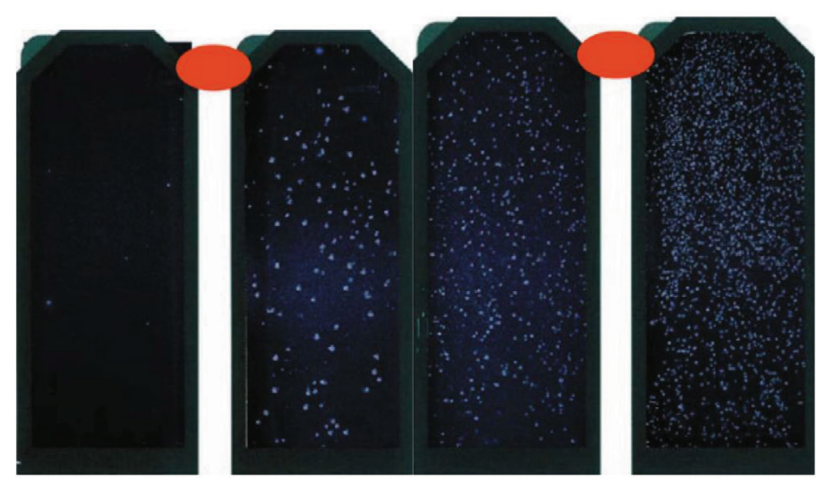

Figure 1. Pictures of colony-forming units show the differences in Streptococcus mutans between group 1, 2, 3, 4 as score 1, 2, 3, 4

\section{Results}

The mothers' sIgA, pH values, buffering capacity, S. mutans and Lactobacilli scores are given in Tables I, II and III. There was no statistically significant difference between the study and the control group of the mothers ( $p>0.05)$.

The infants' salivary IgA and $\mathrm{pH}$ values did not show any statistically significant difference after 3 weeks in both groups (Tables IV and V) ( $p>0.05)$. S. mutans and Lactobacilli score changes showed no statistically significant difference (Table VI). However, there was a statistically significant increase in the buffering capacity of saliva after 3 weeks of probiotic yogurt consumption $(p=0.04)$ (Table VI).

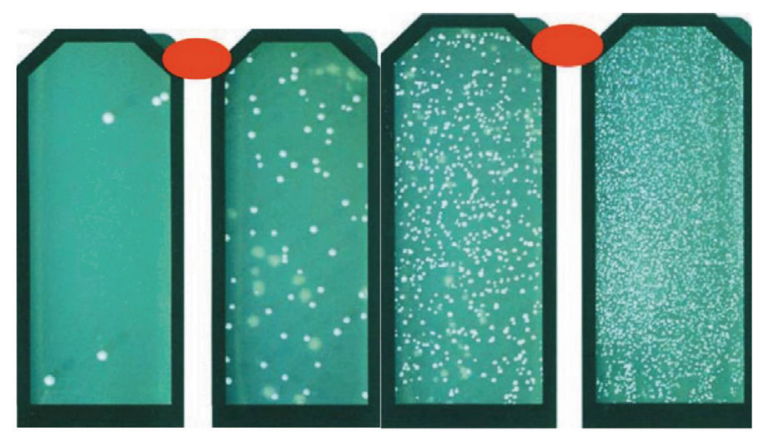

Figure 2. Pictures of colony-forming units show the differences in lactobacilli between group 1, 2, 3, 4 as score 1, 2, 3, 4

\begin{tabular}{|c|c|c|}
\hline & $\mathrm{pH}$ & slgA \\
\hline & $\begin{array}{l}\mathrm{pH} \pm \\
\text { Standard } \\
\text { deviation }\end{array}$ & $\begin{array}{l}\mu \mathrm{g} / \mathrm{mL} \pm \\
\text { Standard } \\
\text { deviation }\end{array}$ \\
\hline Mothers in control group (n) & $7.27 \pm 0.52$ & $32.24 \pm 19.77$ \\
\hline Mothers in study group (n) & $6.87 \pm 0.35$ & $46.88 \pm 22.98$ \\
\hline
\end{tabular}

slgA: Secretory immunoglobulin A

Table II. Buffering capacity of saliva of mothers

\begin{tabular}{|l|l|l|l|}
\hline Saliva buffer capacity & Low & Medium & High \\
\hline Mothers in control group $(n)$ & 0 & 0 & 10 \\
\hline Mothers in study group $(n)$ & 0 & 4 & 6 \\
\hline
\end{tabular}

Table III. Scores of Streptococcus mutans and lactobacilli of mothers

\begin{tabular}{|l|l|l|l|l|l|l|l|l|}
\hline & \multicolumn{3}{|l|}{$\begin{array}{l}\text { Streptococcus } \\
\text { mutans scores }\end{array}$} & \multicolumn{4}{|l|}{ Lactobacilli scores } \\
\cline { 2 - 9 } & $\mathbf{1}$ & $\mathbf{2}$ & $\mathbf{3}$ & $\mathbf{4}$ & $\mathbf{1}$ & $\mathbf{2}$ & $\mathbf{3}$ & $\mathbf{4}$ \\
\hline $\begin{array}{l}\text { Mothers in control } \\
\text { group (n) }\end{array}$ & 2 & 2 & 5 & 1 & 2 & 3 & 3 & 2 \\
\hline $\begin{array}{l}\text { Mothers in study } \\
\text { group }(\mathrm{n})\end{array}$ & 0 & 5 & 3 & 2 & 2 & 0 & 3 & 5 \\
\hline
\end{tabular}


Table IV. Infants' slgA values at baseline and after 3 weeks

\begin{tabular}{|l|l|l|}
\hline & $\begin{array}{l}\text { Baseline IgA } \\
\text { levels }(\mu \mathrm{g} / \mathrm{mL})\end{array}$ & $\begin{array}{l}\text { 3 weeks after } \mathbf{l g A} \\
\text { levels }(\mu \mathrm{g} / \mathrm{mL})\end{array}$ \\
\hline Control group, $(\mathrm{p}>0.05)$ & $13.11 \pm 14.98$ & $14.05 \pm 19.20$ \\
\hline Study group, $(\mathrm{p}>0.05)$ & $15.49 \pm 17.95$ & $18.87 \pm 35.24$ \\
\hline
\end{tabular}

slgA: Secretory immunoglobulin $A$

Table V. Infants' pH values at baseline and after 3 weeks

\begin{tabular}{|l|l|l|}
\hline & $\begin{array}{l}\text { Baseline } \\
\text { pH } \pm \text { SD }\end{array}$ & $\begin{array}{l}\text { 3 weeks after } \\
\text { pH } \pm \text { SD }\end{array}$ \\
\hline Infants in control group $(n),(p>0.05)$ & $7.11 \pm 0.53$ & $7.23 \pm 0.77$ \\
\hline Infants in study group $(n),(p>0.05)$ & $6.98 \pm 0.57$ & $7.08 \pm 0.68$ \\
\hline
\end{tabular}

SD: Standard deviation

Table VI. Infants' Streptococcus mutans, Lactobacilli and buffering capacity changes after 3 weeks of probiotic yogurt consumption

\begin{tabular}{|l|l|l|}
\hline & $\begin{array}{l}\text { Study group } \\
(\mathbf{n}=\mathbf{1 1})\end{array}$ & $\begin{array}{l}\text { Control group } \\
(\mathbf{n}=\mathbf{9})\end{array}$ \\
\hline \multirow{3}{*}{ Streptococcus mutans, $(\mathrm{p}>0.05)$} & $3^{\mathrm{a}}$ & $1^{\mathrm{a}}$ \\
& $2^{\mathrm{b}}$ & $0^{\mathrm{b}}$ \\
$6^{\mathrm{c}}$ & $8^{\mathrm{c}}$ \\
\hline \multirow{4}{*}{ Lactobacilli, $(\mathrm{p}>0.05)$} & $2^{\mathrm{a}}$ & $0^{\mathrm{a}}$ \\
& $3^{\mathrm{b}}$ & $0^{\mathrm{b}}$ \\
\hline \multirow{3}{*}{ Buffering capacity of saliva, } & $6^{\mathrm{c}}$ & $9^{\mathrm{c}}$ \\
$(\mathrm{p}=0.04)$ & $0^{\mathrm{a}}$ & $1^{\mathrm{a}}$ \\
& $4^{\mathrm{b}}$ & $4^{\mathrm{b}}$ \\
\hline
\end{tabular}

a: Values after 3 weeks < baseline values, b: Values after 3 weeks $>$ baseline values, c: Values after 3 weeks=baseline values

\section{Discussion}

It is well known that the dynamics of immature microbiota colonization of infants can be changed with diet to the benefit of oral health (21). During the last decades, an intake of probiotics has been suggested to prevent dental caries (22). However, oral probiotic bacteria colonization in the oral cavity were defined as temporary. However, so far, studies have been carried out on subjects with mature microbiota. Currently, infants with immature oral microbiota have become the center of attention since early probiotic intervention may have a prolonged benefit on oral health $(7,23)$.

The uniqueness of our study is that full term infants with immature oral microbiota were subjected to a shortterm administration of probiotics. Our hypothesis was short-term early exposure to probiotics may alter oral microbiota and eliminate eliminate caries risk factors in infants. The duration of the intake of probiotics in studies varies however, both short- and long-term use have been reported to affect oral health and reduce caries risk factors (2,6-15). Hence, the present study was designed to see the short-term effect of probiotics.

Breast milk is the most important probiotic sources which promotes colonization with lactobacilli more effectively than formula feeding (24). In the present study, all included infants were breastfed. During weaning, a probiotic existence in the gut and oral cavity is maintained through products like yogurt which is effective, practical and acceptable among infants (25). Hence, probiotic containing yogurt was consumed in our study. In this product, there are triple probiotic cultures (B. Longum BB536, B. Bifidum Bb12, L. Rhamnosus HNO01) and prebiotic fiber feeding these cultures, all of which help to regulate the digestive system and support the immune system of the baby (25). As for the oral health benefit, a study by Lin et al. (26) showed that short-term intake of yogurt in children resulted in a significant rise in $\mathrm{pH}$ value and cariostatic effects on biofilm acidogenicity. In general, the underlying mechanism of action is considered the same as those described for the intestine. Oral colonization competition with oral pathogens for adhesion sites, nutrients and enhancing the host immune responses can be counted as the mechanism of action. The bactericidal and bacteriostatic characteristics of probiotics derive from their production of antimicrobial agents like organic acids, hydrogen peroxide, antifungal compounds (23).

The lack of a difference between baseline and 3 weeks after probiotic intake can be due to the short duration of use. Our findings are not in line with several studies that suggest probiotic lactobacilli or Bifidobacterial decrease salivary mutans streptococci (7). Nevertheless, unchanged scores for salivary mutans streptococci have also been reported (10). Likewise, Hasslöf et al. (27) reported that early intervention with probiotic had no long-term effect on the caries experience.

Salivary oral immune response after probiotic use was also investigated by researchers. However, total slgA levels were reported to be unaffected (28). In our study, salivary slgA levels were measured by ELISA test after starting probiotic yogurt use in 6-8 month-old infants. Although there was a slight increase in slgA levels after 3 weeks of probiotic yogurt consumption, the difference was not statistically significant. Likewise, in a study by Stensson et al. (20), slgA was reported to show a tendency to increase, however, this was not found to be statistically significant. Our result is also in line with the dental literature (28). However, the long-term effect is worth investigating with a higher sample size. 
Probiotic bacteria produce many substances that affect the mouth flora. These substances can alter the $\mathrm{pH}$ or oxidation/reduction potential of dental plaque and saliva, affecting cariogenic bacteria survival. Subsequently, saliva $\mathrm{pH}$ and buffering capacity may be affected (29). In the present study, buffering capacity rose after 3 weeks of probiotic yogurt consumption. Since buffering capacity is a measure to alleviate the caries condition, the use of probiotic can be recommended to increase the buffering capacity of children with high caries risk.

We had several study limitations. Firstly, bacteriological evaluation was assessed by chair side kits. Secondly, this study was limited to a three-week period. The effect of the long-term use of probiotic products is still challenging to research. Thirdly, B. Longum BB536, B. Bifidum Bb12, L. Rhamnosus HN001 was assessed in this study. However, different strains of probiotics may have different effects on oral health.

\section{Conclusion}

Consequently, even short-term probiotic yogurt intervention in infants during the early stages of life might have benefits for oral health. Further studies with both short- and long-term use of probiotics must be implemented in infants to confirm the results and see the effects on other caries risk factors.

\section{Ethics}

Ethics Committee Approval: Ethical approval was given by the Research Ethics Committee at Ege University Faculty of Medicine (approval number: 12-8/24).

Informed Consent: Informed consent for infants was provided by their parents.

Peer-review: Externally peer-reviewed.

\section{Authorship Contributions}

Surgical and Medical Practices: E.E., A.T.A., E.ER., G.A., F.Ö., Concept: E.E., A.T.A., E.ER., G.A., F.Ö., Design: E.E., F.Ö., G.A., Data Collection or Processing: E.E., A.T.A., E.ER., Analysis or Interpretation: E.E., A.T.A., E.ER., G.A., F.Ö., Literature Search: A.T.A., E.E., Writing: A.T.A., E.E.

Conflict of Interest: No conflict of interest was declared by the authors.

Financial Disclosure: The authors declared that this study received no financial support.

\section{References}

1. Çağlar E, Kargul B, Tanboga I. Bacteriotherapy and probiotics' possible role on oral health. Oral Dis 2005;11;131-7.

2. Cogulu D, Topaloglu-Ak A, Caglar E, et al. Potential effects of a multistrain probiotic-kefir on salivary Streptococcus mutans and Lactobacillus spp. J Dent Sci 2010;5:144-9.
3. Thomas DW, Greer FR. Probiotics and prebiotics in pediatrics. Pediatrics 2010;126:1127-31.

4. Lenoir-Wijnkoop I, Sanders ME, Cabana MD, et al. Probiotic and prebiotics influence beyond the intestinal tract. Nutrition Rev 2007;65:469-89.

5. Reid G, Burton J. Use of Lactobacillus to prevent infection by pathogenic bacteria. Microbes Infect 2002;4:319-24.

6. Caglar E, Cildir SK, Ergeneli S, Sandalli N, Twetman S. Salivary mutans streptococci and lactobacilli levels after ingestion of the probiotic bacterium Lactobacillus reuteri ATCC 55730 by straws or tablets. Acta Odontol Scand 2006;64:314-8.

7. Näse L, Hatakka K, Savilahti E, et al. Effect of long-term consumption of a probiotic bacterium, Lactobacillus rhamnosus CG, in milk on dental caries and caries risk in children. Caries Res 2001;35;412-20.

8. Nikawa H, Makihira S, Fukushima H, et al. Lactobacillus reuteri in bovine milk fermented decreases the oral carriage of mutans streptococci. Int J Food Microbiol 2004;95;219-23.

9. Ahola Al, Yli-Knuuttila $H$, Suomalainen $T$, et al. Short-term consumption of probiotic-containing cheese and its effect on dental caries risk factors. Arch Oral Biol 2002;47:799-804.

10. Montalto $M$, Vastola $M$, Marigo $L$, et al. Probiotic treatment increases salivary counts of lactobacilli: a double-blind, randomized controlled study. Digestion 2004;69:53-6.

11. Caglar E, Sandalli N, Twetman S, Kavaloglu S, Ergeneli S, Selvi S. Effect of yoghurt with Bifidobacterium DN-173 010 on salivary mutans streptococci in young adults. Acta Odontol Scand 2005;63:317-20.

12. Caglar E, Kuscu OO, Cildir SK, Kuvvetli SS, Sandalli N. A probiotic lozenge administered medical device and its effect on salivary mutans streptococci and lactobacilli. Int I Paediatr Dent 2008; 18:35-9.

13. Caglar E, Kuscu OO, Cildir SK, Kuvvetli SS, Sandalli N, Twetman $\mathrm{S}$. Effect of an ice-cream containing Bifidobacterium lactis Bb-12 on salivary mutans streptococci and lactobacilli. Acta Odont Scand 2008;66:154-8.

14. Çaglar E, Kavaloglu SC, Kuscu OO, Sandalli N, Holgerson $\mathrm{PL}$, Twetman S. Effect of chewing gums containing xylitol or probiotic bacteria on salivary mutans streptococci and lactobacilli. Clin Oral Invest 2007;11:425-9.

15. Cildir SK, Germec D, Sandalli N, et al. Reduction of salivary mutans streptococci in orthodontic patients during daily consumption of yoghurt containing probiotic bacteria. Eur I Orthod 2009;31:407-11.

16. Ghisolfi J, Roberfroid M, Rigo J, Moro G, Polanco I. Infant formula supplemented with probiotics or prebiotics: never, now or someday? I Pediatr Gastroenterol Nutr 2002;35:467-8.

17. Ushida N, Ishihara K, Kobayashi N, Matsukubo T, Yakushiji M, Okuda K. Initial acquisition and transmission of Streptococcus mutans from lapanese mothers to children. Pediatr Dent I 2009;19:98-105.

18. Li Y, Caufield PW. The fidelity of initial acquisition of mutans Streptococci by infants from their mothers. I Dent Res 1995;74:681-5.

19. Wan AK, Seow WK, Purdie DM, Bird PS, Walsh L), Tudehope DI. Oral colonization of Streptococcus mutans in six-month-old predentate infants. J Dent Res 2001;80:2060-5.

20. Stensson M, Koch G, Coric S, Abrahamsson TR, Jenmalm MC. Oral Administration of Lactobacillus reuteri during the first year of life reduces caries prevalence in the primary dentition at 9 years of age. Caries Res 2004;48:111-7.

21. Featherstone JD. Prevention and reversal of dental caries: role of low level flüoride. Community Dent Oral Epidemiol 1999;27:31-40. 
22. Lin $\mathrm{TH}$, $\mathrm{Lin} \mathrm{CH}$, Pan $\mathrm{TM}$. The implication of probiotics in the prevention of dental caries. Appl Microbiol Biotechnol 2018;102:577-86.

23. Twetman S, Stecksen-Blicks C. Probiotics and oral health effectsin children. Int I Paediatric Dent 2008;18:3-10.

24. Holgerson PL, Vestman NR, Claesson R, et al. Oral Microbial profile discriminates breastfed from formula-fed infants. I Pediatr Gastroenterol Nutr 2013;56:127-36.

25. Lourens-Hatting A, Viljoen BC. Yogurt as probiotic carrier food. Int Dairy Hournal 2001;11:1-17.

26. Lin YTJ, Chou CC, Hsu CYS. Effect of Lactobacillus casei Shirota intake on caries risk in children. J Dent Sci 2017;12:179-84.
27. Hasslöf P, West CE, Videhult FK, Brandelius C, Stecksén-Blicks C. Early intervention with probiotic Lactobacillus paracasei F19 has no long-term effect on caries experience. Caries Res 2013;47:559-65.

28. Jorgensen MR, Keller MK, Kragelund C, et al. Lactobacillus reuteri supplements do not affect salivary IgA or cytokine levels in healthy subjects: A randomized, double-blind, placebo-controlled, crossover trial. Acta Odontol Scand 2016;74:399-404.

29. Gillor O, Etzion A, Riley MA. The dual role of bacteriocins as anti- and probiotics. Appl Microbiol Biotechnol 2008;81:591606. 